\title{
A conceptual approach to the use of Cost Benefit and Multi Criteria Analysis in natural hazard management
}

\author{
C. D. Gamper ${ }^{1,2}$, M. Thöni ${ }^{1,2}$, and H. Weck-Hannemann ${ }^{1,2}$ \\ ${ }^{1}$ alpS Centre for Natural Hazard Management, Innsbruck, Austria \\ ${ }^{2}$ Institute of Public Finance, University of Innsbruck, Innsbruck, Austria
}

Received: 25 July 2005 - Revised: 22 February 2006 - Accepted: 22 February 2006 - Published: 8 May 2006

\begin{abstract}
Decision-making for protection measures against natural hazards entails major complexities for final decision makers. The issue in question does not only implicate a variety of criteria that need to be considered but also scarce financial resources make the allocation decision a difficult task. Furthermore, these decisions appear to be multidisciplinary in nature. Stakeholders from experts over politicians and the public are among the affected parties in making and dealing with the consequences of such decisions. In order to capture the complexity that arises when incorporating the varieties of interests as well as impacts protection measures have on the environment, the economy and society, transparent and multidisciplinary decision support techniques are needed. This paper looks at how Cost Benefit Analysis (CBA), a tool already applied to decisions concerning protective measures, and Multi Criteria Analysis (MCA), even though new to the field as such but already successfully practiced in other environmental areas, perform according to the abovementioned criteria. A conceptual overview of the methodologies will be given along with a discussion of the respective strengths and weaknesses. Looking at past applications, this overview gives an analysis about the potential of socio economics in its contribution to natural hazard research.
\end{abstract}

\section{Introduction}

Decisions made in natural hazard management in general and for protective measures in specific, can be characterised as environmental decisions, not only because the issue in question is nature, but also because of the characteristics generally known from environmental decisions.

Correspondence to: C. D. Gamper

(gamper@alps-gmbh.com)
From a socio-economic perspective the environment is a public good. Such a good is characterised by non-rivalry meaning that public goods are goods for which consumption by any one individual does not detract from the ability of others to consume them. Furthermore, it is characterised by nonexclusivity, in other words by indivisibility ("all or nothing" provision) and collective consumption (individuals cannot be excluded from consumption) (Edwards-Jones et al., 2000). Contrary to private goods, there is no market which takes over the decision process for allocating the goods (Connolly and Munro, 1999). This so called market failure with public goods is compensated by the state taking over the decision responsibility. So, instead of individuals it is the state that decides on resource allocation. In democratic systems the decision responsibility of the state and other decision mechanisms is given to politicians who - as representatives of the population - have an incentive to make decisions based on the general will of the people as they strive to be reelected (Mueller, 2003).

In the case of environmental issues, and therefore protective measures against natural hazards, politicians are confronted with a complex choice. Environmental decisions affect a multiplicity of parties, from individuals as consumers or organisations of producers to tax payers. Also, the modes of environmental decision making, as well as the underlying assumptions, tools and criteria are highly diverse and add on to this multiplicity in decision-making. Take protection measures as an example: for the proper installation of avalanche protection measures the civic, geological, legal or meteorological experts' opinions are needed as well as environmental, economic, ecological and social criteria have to be regarded.

In order to overcome this complexity, politicians need decision support systems that help them to generate an information basis that provides for finding the most transparent, equitable and economically efficient solutions. A decision

Published by Copernicus GmbH on behalf of the European Geosciences Union. 


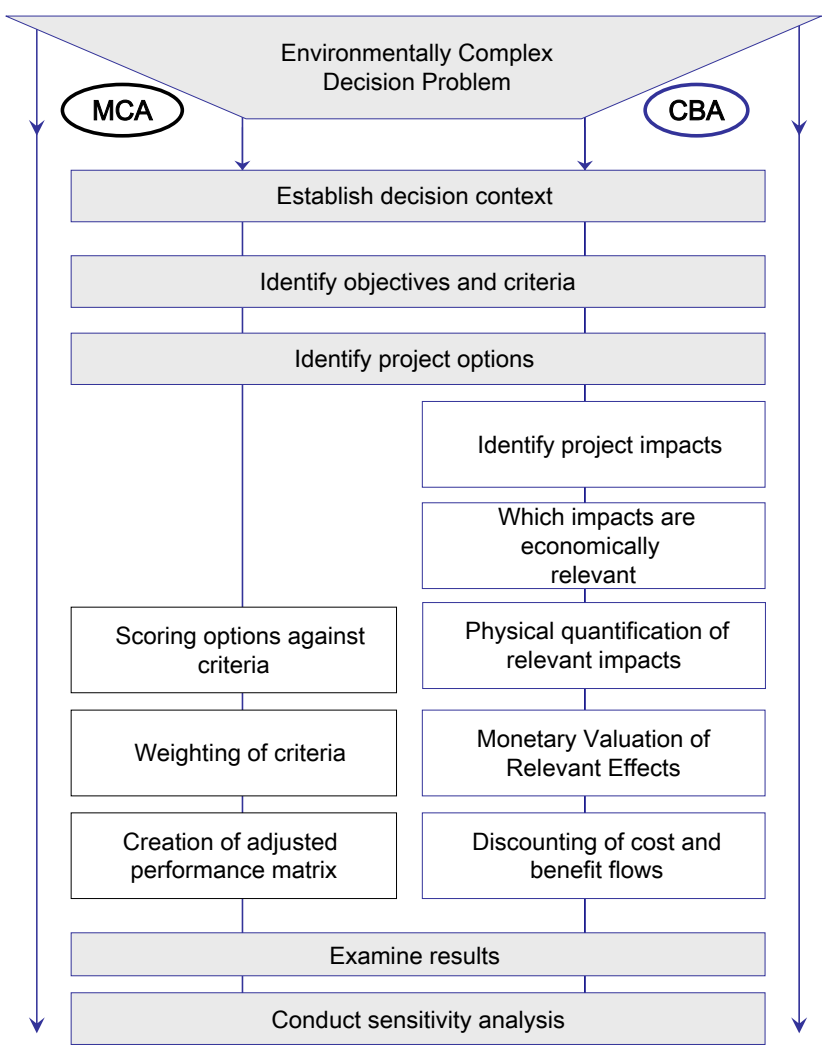

Fig. 1. The methodological steps of CBA and MCA in comparison.

support system can be defined as an interactive system that is able to produce data and information and, in some cases, even promote understanding related to a given application domain in order to give useful assistance in resolving complex and ill-defined problems (Cavallaro and Ciraolo, 2005). Based on this set of information generated from decision support systems, politicians are able to evaluate the most consensual alternative that not only serves the widest share of preferences but also the utility of the decision maker in terms of improving her chances to stay in office for another legislative period. Therefore, decision support systems should be capable of incorporating various stakeholders' preferences as well as a wide set of criteria against which alternative solutions can be weighed.

The methods underlying this paper are two examples that satisfy these objectives. Cost Benefit Analysis (CBA) and Multicriteria Analysis (MCA) are often used in the environmental economic area. The emphasis of these tools lies in providing a sound basis for decision makers' information to consider the alternative projects and to choose the optimal solution. Both CBA and MCA, try to present information in a reasoned, consistent and orderly way open to the interpretation of the decision maker (Joubert et al., 1997). It is noteworthy that CBA and MCA aim at constructing or creat- ing information that can be useful to an actor taking part in a decision process.

Both methods have their origins in environmental economics and hence have been applied to various environmental decision contexts. CBA has already found its users in natural hazard management. For example, Bründl et al. (2005) or Fuchs and McAlpin (2005) applied the cost benefit approach to the analysis of risk and preventive measures against avalanches in Switzerland, while Wilhelm (1997) has studied the economic efficiency of preventive measures against avalanches extensively. In terms of legitimacy of CBA in natural hazard studies, the method is, among other countries, required by law for major expenditure decisions on protective measures in Austria. MCA has not been applied explicitly to this context; therefore it is one goal of this paper to show that there is high potential in making use of MCA in this policy and research area.

In the following paper, a conceptual overview of the two methods is given. At first, the two methodologies are described in terms of their characteristics and implementation procedure. It is shown that both methods appear to have the same starting points and then move towards different directions to come to their results and propositions. Based on these understandings, a discussion of the divergences and commonalities of the methods will follow in order to then show where both methods can be applied to in practice. Finally, a conclusion is drawn on the paper's impact on the current natural hazard discussions and future potential research activities will be outlined.

\section{The methodologies - CBA and MCA: main character- istics and implementation structure}

The objective of CBA is to facilitate a more efficient allocation of society's resources (Boardman et al., 2001). The method seeks to translate all relevant considerations into monetary terms and can therefore select the most efficient project from a portfolio of alternatives (Hanley and Spash, 1993).

"Multicriteria Analysis can be defined as the study of methods and procedures by which concerns about multiple conflicting criteria can be formally incorporated in a decision making process" (International Society on MCDM, 2004). So, if, for example, $O$ is a finite set of $n$ feasible options and $G$ is a set of $m$ evaluation criteria, it is possible to build an $n x m$ matrix $(\mathbf{P})$, whose elements $p_{i, j}=g_{j}\left(o_{i}\right)(i=1,2, \ldots n$; $j=1,2, \ldots . m)$ represent the evaluation of option $i$ by means of criterion $j$. An option $o_{1}$ is evaluated to be better than option $o_{2}$ (both belonging to the set $O$ ) according to the $j$ th criterion if $g_{j}\left(o_{1}\right)>g_{j}\left(o_{2}\right)$ (Munda, 1995).

CBA as well as MCA build on the idea of aggregating information flows of costs and benefits of different projects. Figure 1 demonstrates that both methods go about this in a similar way. 


\subsection{Similarities of CBA and MCA}

Step 1:

CBA \& MCA: establishing the decision context

The first step of establishing the decision context involves outlining the aims as well as identifying decision makers and other stakeholders. An institutional compilation, performed mainly on historical, legislative and administrative documents, can be used to achieve this. The map of actors resulting from this analysis might find adjustments during the process of the MCA (De Marchi et al., 2000). A shared understanding of the decision context that is the political, social, economic and administrative structure, is essential because the impacts can be manifold and a lot of people may be affected whose preferences and perceptions need to be recognised (Omann, 2004).

The elicited information of this step has immediate consequences for the remaining work of the MCA, whereas in CBA this information is fundamental but only influences the further analysis to a mediate extent. For MCA, it is essential to know when and how stakeholders contribute to the analysis as well as in what form and how this implementation constitutes the design of the social and technical system for conducting the MCA (Dogson et al., 2001).

Step 2:

CBA \& MCA: identify objectives and criteria

Objectives can be created either using a top-down approach, in the case of having a larger project where objectives need to be set by a central body, or a bottom-up approach, where various stakeholders participate in generating objectives (Edwards-Jones et al., 2000). An overall objective can be broken down into a subset of objectives, thus higher level goals are dependent on lower level ones: in natural hazard management, a higher level of security might be the main aim when installing protective measures against avalanches, but at the same time a sub-goal could be to minimise the environmental impact (i.e. the loss of biodiversity incurred through the building of high altitude feeder roads). Goals need to be clear, specific, measurable, agreed, realistic and time-dependent, that means being classified into long-term or immediate goals.

Only MCA identifies the criteria that allow measuring the strength of the options in fulfilling the objectives in this step. To meet this requirement, a criterion needs to be measurable, if not quantitatively, then qualitatively, to show how well an option performs in relation to that criterion (Dogson et al., 2001). In the example above, a possible criterion could be the number of species lost through human induced behaviour.

The finalisation of the chosen criteria requires assessing them against a range of qualities: criteria should be complete, operational, decomposable (two factors should not be in opposition in a single criterion), non-redundant, minimal and defined in terms of time (Belton and Stewart, 2002). The time-definition (temporary consequences or permanent ones) brings in difficulty when aggregating and comparing the results. With monetary techniques, discounting is a reasonably well established procedure for aggregation. Apart from the fact that this might not always be plausible to do, this does not solve the problem with criteria measured in terms other than monetary (for a discussion about setting discount rates see Hanley and Spash, 1993; Hackl and Pruckner, 1994).

In MCA, criteria should be developed through participation of the stakeholders, in order to make sure all interests are represented and can then be regarded when conducting the analysis (Stirling and Mayer, 2000).

Step 3:

CBA \& MCA: identify the project options

The third step involves identifying all relevant options for achieving the objectives. The number of options may vary between 2 (e.g. should a certain project be undertaken or not?), any discrete number (i.e. 10 different ways for building protection measures against avalanches) and infinity (Fandel and Spronk, 1983). In the first case, we speak of a 0-1 choice system where one chooses between the current and a new situation (Munda, 1995); in the second case we have a finite number of options available. Fandel and Spronk (1983) suggest creating a subset of alternatives in case of a high number of options. Given the complexity of decision making problems, it is not always possible to define the set of options a priori. In a continuous situation, the set of options is progressively elaborated (Munda, 1995) such as MCA is used to specify the best option under given constraints, like i.e. costs (Dogson et al., 2001).

\subsection{Differences of CBA and MCA}

The next steps before examining the results are conducted quite differently by both methodologies and thus require separate consideration:

Step 4:

CBA: identification of project impacts

This step comprises the identification of all impacts resulting from the implementation of the project (Hanley and Spash, 1993). Regarding protective measures such impacts can be, e.g. the resources used in the construction or the effects on local property prices. These impacts have to be qualified and categorised so that one can divide them in positive and negative ones. Positive impacts are reflected in better individual supply with consumer goods and consequently lead via higher consumer satisfaction to an increase in welfare. A negative effect means a shift of resources which would have lead to an increase in welfare in an alternative use. 
Step 5:

CBA: which impacts are economically relevant?

In economic terms positive and negative impacts are understood as benefits and costs.

Positive effects in general can be seen on the one hand as a qualitative or quantitative increase in goods and services, and on the other hand as a price reduction, both generating a benefit. In contrast a qualitative or quantitative decrease in consumer goods and/or a price increase are negative effects and therefore costs. These negative impacts also include opportunity costs, since e.g. an hour of labour or a bag of cement that is used up in constructing a protective measure cannot be used simultaneously in constructing a dam. The following table (see Table 1) exemplifies possible costs and benefits arising from the implementation of an alpine protective measure.

In order to treat something as an impact within CBA, we have to know if there is a cause-and-effect relationship between some physical outcome of the project and the utility of human beings withstanding (Boardman et al., 2001). Thereby it is not relevant whether a market for the specific effect exists or not. The priceless impacts are referred to as externalities which can either be positive or negative and which display public good aspects in terms of non-rivalry and non-excludability.

Finally it is important to mention that some impacts have to be excluded to avoid the possible case of a double count. Transfer payments exemplify this case and can be found in the reductions of indirect tax revenue due to a project going ahead, or additional unemployment benefits becoming payable. Neither of these flows constitutes a using-up of real resources, such as labour hours, but is merely a redistribution of money through the government (Hanley and Spash, 1993).

Step 6:

CBA: physical quantification of relevant impacts

This stage involves the physical quantification of the above mentioned flows by measuring all positive and negative effects, including the time they will occur (Boardman et al., 2001). Again, in the case of the implementation of a protective measure, the analyst has to determine the number of protected lives or protected real assets, the dimension of landscape destruction or the number of years the measure will last before maintenance work has to be done. In addition to this step, it is of great importance to consider the varying levels of uncertainty by taking the probability of occurrence into account, in order to calculate, if possible, the expected value.
Step 7:

CBA: monetary valuation of relevant effects

As a next step each of the economically relevant impacts has to be monetarised to make a monetary equation between costs and benefits possible. This monetarisation is a workable task as long as the analyst can find market prices to evaluate certain impacts, such as buildings, cars or infrastructure. If the reverse occurs and economists have to work with non-market goods, like human lives or the value of recreation, the willingness to pay (WTP) concept is generally used to determine the monetary value of certain impacts. The respective valuation methods are usually divided into direct and indirect approaches. While indirect methods seek to recover estimates of individuals' WTP for environmental quality by observing their behaviour in related markets, and thus their appropriate demand curve, the direct methods infer individual valuation for environmental quality directly, by asking them to state their WTP for the environment (Hanley and Spash, 1993). Indirect methods are e.g. the hedonic pricing approach, the travel cost and avoidance cost method. Using hedonic pricing, for example, the related market for protective measures is the real estate market and economists seek to infer individuals' valuation of protective measures by considering their behaviour in this market (for detailed theoretical discussions see Rosen, 1974; Graham, 2001; Thöni, 2005; Weck-Hannemann, 1994; for applications see Elsasser, 1996; Löwenstein, 1994). The most widely used direct method is the contingent valuation approach, which, in short, consists of directly questioning people about their maximum willingness to pay e.g. for a certain risk reduction (for a detailed theoretical discussion see Pruckner, 1995; Navrud and Pruckner, 1997; Römer, 1991; for applications see Pruckner, 1993; Kämmerer et al., 1996; Degenhardt et al., 1997).

These briefly described methods reveal people's preferences and these are then reflected by monetary values in the analysis that enable the comparison between costs and benefits.

Step 8:

CBA: discounting of cost and benefit flows

Once all relevant costs and benefits have been expressed in monetary amounts, it is necessary to convert them all into present value (PV) terms so to take the time value of money and/or time preferences into account of the analysis (Hanley and Spash, 1993). Benefits and costs are homogenised by using a discount rate that discounts future relative to present benefits and costs in order to obtain their present values. The choice of the appropriate discount rate is still contentious and can therefore differ i.e. between 4 and 12 percent (Boardman et al.; 2001, Hackl and Pruckner, 1994). For discount rates used in the applications of natural hazards see e.g. Wilhelm (1997 or 1999). 
Table 1. Possible costs and benefits of an alpine protective measure.

\begin{tabular}{ll}
\hline Costs & Benefits \\
\hline & \\
- building costs (material, explosives, per- & - prevented material damage \\
sonnel costs) & - modified possibilities of land use \\
- maintenance work & - prevention of injuries \\
- evacuation costs & - protection of human life/reduction of \\
- change in landscape & fatalities \\
\hline
\end{tabular}

Step 4:

MCA: scoring options against criteria

There are different techniques of MCA available; some require complete information from decision makers about their objectives, others are more participative working with decision makers to clarify their priorities. Again others analyse problems without relying on preference information at all (Edwards-Jones et al., 2000). Nonetheless, there are steps that all MCA's have in common (outlined in Fig. 1). (A comprehensive overview of the available MCA techniques is given in Omann (2004) and Gamper (2004)).

The creation of the performance matrix requires the determination of the relationships between options and their impacts on criteria. More precisely, this step follows in two parts: scoring and weighting.

So far, the different options have different measures (e.g. biodiversity loss is measured in numbers, direct costs are measured in monetary units) attached to them. Because one cannot compare different measures straight away, a common one in terms of a scale needs to be found. If we face multiple attributive decisions, a numerical scale is created to deal with this complexity. For more simplified decision structures, this is not necessary and an easy dominant or outranking relation can be evaluated (for further details see Fandel and Spork, 1983 or Vincke et al., 1989).

Usually a scale is chosen between 0 and 100 . So, for example, if there are 3 different technical solutions to build avalanche barriers and the first one costs 30 Million Euros, the second 40 and the third 50, then the first solution will be allotted with a score of 100 as it is the cheapest option and the last one with a score of 0 as it is the most expensive one.

Now, the way this information is processed (What is the score for technical solution 2?) depends on the particular MCA method that is used. Basically, one can go about this scoring process by building a value function and simply reading off values in a function given the lowest and highest scores. Another approach is to use an interval scale through the integration of expert judgements (direct rating). In a third way, one can choose an indirect method through let- ting experts make verbal pairwise assessments. Analytical Hierarchy Process or Rembrandt and Macbeth (Belton and Stewart, 2002) are examples for conducting these steps. As above mentioned (introduction for 2.2), a detailed outline of the available methods is omitted here because of the limited scope of this paper. Refer to the above given references for a complete overview.

Once the alternatives and the relevant criteria are defined, the criterion scores can be determined and consequently an impact matrix can be constructed (second part). A matrix can then take the following look (see Table 2).

Scores are now needed to be analysed through the weighting and aggregation procedure:

Step 5:

MCA: weighting of criteria

Alternatives still can not be compared as a unit of preference since the values do not as yet reflect preferences as such. In taking the exemplary matrix from Table 2 , this could mean that a local governor might find the subsidisation criterion more important than the biodiversity one, as opposed to the ecologist's expertise who finds biodiversity utmost important.

As a consequence, weights can be seen as trade-off values, indicating how much of one criterion you would be prepared to give up in return for an improvement on another criterion (Belton and Vickers, 1990). This assignment of weights can again be operationalised through allotting each criterion or objective a certain share of the overall sum (subsidisation criterion gets 40 out of 100 points from the representative stakeholder). Thus, the weight on a criterion reflects both the range of difference of the options, and how much that difference matters (Dogson et al., 2001). Again, these weights are taken into the impact matrix, this time an option's score on a criterion is being multiplied with its weights. After assigning this to all criteria the sum of these products gives the overall preference for that option. This process is repeated for each of the option and finally a rank can be given to each option's score (Dogson et al., 2001). 
Table 2. Example for impact matrix of a protection measure.

\begin{tabular}{llllc}
\hline Criteria/Options & No Avalanche Barrier & $\begin{array}{l}\text { Technical Solution 1 } \\
\text { for an Avalanche } \\
\text { Barrier }\end{array}$ & $\begin{array}{l}\text { Technical Solution 2 } \\
\text { for an Avalanche } \\
\text { Barrier }\end{array}$ & $\begin{array}{l}\text { Technical Solution } 3 \\
\text { for an Avalanche } \\
\text { Barrier }\end{array}$ \\
\hline $\begin{array}{l}\text { Economic } \\
\begin{array}{l}\text { Direct (financial) costs } \\
\text { Environmental }\end{array}\end{array}$ & 0 Mil. Euros & 10 Mil. Euros & 20 Mil. Euros & 30 Mil. Euros \\
$\begin{array}{l}\text { Environmental Impact Assessment }- \\
\text { loss of biodiversity } \\
\text { Social } \\
\text { Number of People being protected }\end{array}$ & 0 loss & Loss of 50 species & Loss of 25 species & Loss of 10 species \\
$\begin{array}{l}\text { Institutional } \\
\text { Subsidisation at national level }\end{array}$ & None & 200 people saved & 100 people saved & 300 people saved \\
\hline
\end{tabular}

Step 6:

MCA: creation of adjusted performance matrix

Once the scores are re-calculated with their weights they can be counted together and a final sum of each option can be given. These scores can be built into the adjusted impact matrix. With these results it will be able to give a ranking of the options (or in the case of simpler models, one option can be recommended).

\subsection{Concluding steps}

Step 9:

CBA \& MCA (Step 7): examine results

Both methods seek to support the selection of projects and policies which are most efficient and optimal.

The interpretation of MCA results can show the differences between the rankings, i.e. say that technical solution 1 is twice as good as solution 2. Furthermore, the results can be illustrated in costs and benefits graphs where a relative value-for-money comparison can be shown (Dogson et al., 2001) and also dominating options drawn out (being cheaper and more beneficial).

The examination of results from CBA can be based on the criterion of net present value (NPV). This test in a first step simply asks whether the sum of discounted gains (PV(B)) exceeds the sum of discounted losses (PV(C)), see Eq. (1) and (2) below. If so, the project can be said to represent an efficient shift in resource allocation, given the data used in the CBA (Hanley and Spash, 1993). All project alternatives representing a positive NPV are qualified for acceptance (3), even though from an economic viewpoint, the one with the highest NPV (max NPV (4)) should be chosen as it represents an optimum.

$$
\begin{aligned}
& \mathrm{PV}(\mathrm{B})=\sum_{t=0}^{n} \frac{B_{t}}{(1+s)^{t}} \\
& \mathrm{PV}(\mathrm{C})=\sum_{t=0}^{n} \frac{C_{t}}{(1+s)^{t}} \\
& \mathrm{NPV}=\mathrm{PV}(\mathrm{B})-\mathrm{PV}(\mathrm{C}) \quad \text { Project acceptance if } \mathrm{NPV}>0 \\
& \mathrm{NPV}_{\mathrm{opt}}=\mathrm{PV}(\mathrm{B})-\mathrm{PV}(\mathrm{C}) \quad \text { Optimal project if max NPV }
\end{aligned}
$$

In addition to the NPV alternatives like the internal rate of return and the benefit-cost ratio can also be used as decision criterions.

Step 10:

CBA \& MCA (Step 8): sensitivity analysis

At least in all ex ante cases of CBA and MCA, it is necessary to make predictions concerning future physical flows, future relative values, as well as a number of criteria and stakeholders. None of these predictions are made with perfect foresight, therefore a sensitivity analysis, as an essential final stage, is conducted (Hanley and Spash, 1993).

The sensitivity analysis aims to discover to which parameters the final outcome is sensitive. These parameters can for example include the discount rate, the physical quantities and qualities of the output or input or the project life span and the number of chosen criteria.

\section{CBA and MCA: a discussion of the commonalities and differences of the underlying ideals}

Even though the two methods show to have a range of commonalities, there are still differences between the evaluation tools CBA and MCA. But as Garrod and Kenneth (1999) put 
it, MCA can be seen as complementing monetary evaluation or decision making methods such as CBA, rather than looking at it as a different method as a whole. According to Edwards-Jones et al. (2000), it is not simply an alternative procedure to these techniques, but rather a formal structure providing for integrating the results from other approaches like CBA. To recapitulate the above methodological summaries, CBA is an analytical way of comparing different forms of input or output, ascribing each unit a monetary value using either market prices, as far as they are available, or economic valuation methods, such as contingent valuation. Even though this procedure is part of and thus their results can be part of MCA, it is not entirely the same as MCA (Brown et al., 2001). MCA includes techniques for comparing impacts in ways, which do not involve giving all inputs and outputs explicit monetary values, but could also include for example other numerical or qualitative measurements.

These and other points have been subject of discussion between the differences and similarities of the two instruments. In the following, a brief outlook of the most widely discussed issues will be given in order to then be able to follow the practical guidelines part where these arguments in favour of or against one of the two methods will be taken into account for the recommendations.

\subsection{Valuation argument}

CBA is intended to facilitate decision-making by giving values to different effects using the common metric 'money' so that the values can be more easily compared and the aggregate outcome more easily appreciated. It therefore reduces a complex environmental problem to something less complex and more manageable. On the other hand, MCA seeks to simplify the complexity of such an issue by making relative comparisons, therefore simply using numerical scales that bring down different measures to a common ground. MCA's decision recommendations are therefore, among the affected parties, more easily accepted since CBA causes difficulties in people's perception when in so far intangible values such as the value of human life are given a monetary value.

\subsection{Comparability argument}

Strong comparability refers to the existence of a single comparative term by which all different actions can be ranked. By putting a common measure, that is money, on losses and gains, CBA aims at achieving strong comparability. But because the environment is a site of conflict between competing values, interests, groups and communities, it is difficult, both time- and labour-wise, to gain methodologically accurate values that fulfil the scientific requirements.

MCA establishes a framework that allows multiple values to be introduced. The scaling down of each value still builds a common measure; nonetheless values remain only relatively comparable instead of the absolute comparability CBA offers. MCA is thus less time and labour consuming to generate and assess values and therefore presents an attractive alternative for analysts.

In essence, the success of both CBA and MCA, as a decision tool for public spending, can be said to be ultimately dependent on the diligence of their execution.

\subsection{Distribution argument}

Given the fact that resources are scarce, it is not enough to consider their availability and distribution solely at present. Future generations take their share in the use of these resources; hence it is of great interest whether the two methods incorporate intra (within a generation) as well as intergenerational (between present and future generations) considerations in their effort to efficiently allocate resources.

\subsubsection{Inter-generation}

Intergenerational considerations are due to uncertainty about the future's generations' preferences difficult to make, they nonetheless have to be assigned a weight in today's resource decisions (Hanley and Spash, 1993). This environmental decision criterion is fulfilled by the explicit application of a discount rate of future project impacts in CBA. Even though, as mentioned already in this paper, the appropriate discount rate is in dispute since it can be arbitrarily set by the analyst, it still accommodates the notion of future generational issues. The discount rate as such finds no application in MCA. The consideration of future generations can be argued to find direct influences in MCA firstly through the range of criteria used to assess project options: by looking at socio-economic, environmental and institutional effects of project impacts, the "holistic" approach needed (according to the Brundtlant Report (WCED, 1983)) for enabling future generations to meet their own needs is implicitly given. Secondly, future generations' interests are represented through stakeholders taking part in the decision process.

\subsubsection{Intra-generation}

Intragenerational issues look at the distribution of resources among the present generation (Edwards-Jones, 2000). This consideration requires the knowledge of affected parties. As already argued in step 1 of the methodological aspects in this paper, CBA and MCA qualitatively describe the range of winners and losers of the potential project alternatives. In the later phase of the analysis, these interests are differently represented in each method: CBA looks at the affected parties by indirectly giving their interests a weight through valuation tools that allow preferences to be revealed in monetary terms. Through various participation processes, stakeholders directly place their weights on the allocation of resource decisions in MCA. 
Table 3. List of Decision Criteria for CBA and MCA ( $Y=Y e s ; N=N o$ ).

\begin{tabular}{lll}
\hline Criterion/Method & CBA & MCA \\
\hline $\begin{array}{l}\text { Decisions: } \\
\text { private Decisions }\end{array}$ & Y & Y \\
public Decisions & $\mathrm{Y}$ & \\
Decision Criterion: & & $\mathrm{Y}$ \\
economic efficiency & $\mathrm{Y}$ & $\mathrm{Y}$ \\
consensus & $\mathrm{N}$ & \\
Valuation: & & $\mathrm{Y}$ \\
quantitative (monetary) & $\mathrm{Y}$ & $\mathrm{Y}$ \\
qualitative & $\mathrm{N}$ & $\mathrm{Y}$ (direct) \\
Participation of Stakeholders & $\mathrm{Y}$ (indirect) \\
Restrictions (qualitative, quantitative) & $\mathrm{Y}$ & $\mathrm{Y}$ \\
Feasibility: & & \\
time-intense & $\mathrm{Y}$ & $\mathrm{N}$ (relative to CBA) \\
budget-intense & $\mathrm{Y}$ & $\mathrm{N}$ (relative to CBA) \\
data-intense & $\mathrm{Y}$ & $\mathrm{Y}$ \\
Transparency & $\mathrm{N}$ & $\mathrm{Y}$ \\
Expert Know-How & $\mathrm{Y}$ & $\mathrm{Y}$ \\
Promotes Understanding of Problem & $\mathrm{N}$ & $\mathrm{Y}$ \\
(Project) Alternatives - from 1 to unlimited number & $\mathrm{Y}$ & $\mathrm{Y}$ \\
\hline
\end{tabular}

\subsection{Multidisciplinary argument}

Environmental policy and natural hazard management are multidisciplinary in nature (Ammann, 2001; Kienholz et al., 2004). Stakeholders from experts over politicians and the voters are among the affected parties in making and dealing with the consequences of such decisions. In order to capture the complexity that arises when incorporating the varieties of interests, transparent and multidisciplinary decision support systems and tools are needed.

CBA's information input for decisions is based on multidisciplinary research while at the same time this information is evaluated based on economic instruments such as hedonic pricing, contingent valuation or travel cost method. MCA on the other hand serves to provide a multidisciplinary approach by incorporating the whole range of criteria stemming from other disciplines.

This multidisciplinarity is furthermore secured in the inclusion of stakeholders in the creation of criteria, alternatives, weights as well as the examination of the outcome.

\section{Implementation guidelines}

As emphasised throughout the present paper, multidisciplinary perspectives and approaches are needed for an integrated assessment of natural hazard management. This issue is also claimed by Steininger and Weck-Hannemann (2002), Ammann (2001) and Kienholz et al. (2004). Consequently, a complexity of knowledge and data is arising that is difficult to arrange for a single final decision maker. The various interests involved in natural hazard management add on to this complexity. This paper has presented a conceptual approach to CBA and MCA in their ability to provide decision support that can help arranging this dense information and bring about a clear structure of the problems at hand.

The decision about whether to use CBA or MCA is difficult to make but can be taken dependent on a range of different criteria. According to the emphasis of the analysis, one can go through Table 3 of criteria in order to take the decision on the use of the respective instrument. This table is on the one hand the sum of most of the arguments discussed in this paper, but also outlines the most distinctive ones in terms of application. It consists of a wide, even though not extensive, range of criteria that can be considered when weighing the two methods against one another. Since the many commonalities of CBA and MCA are reflected here as well, the table does not easily lead - and is also not intended to - an analyst to the choice of the suitable method. Different authors (like e.g. Bosch and Kahn, 2003; Brouwer and van Ek, 2004; van Pelt, 1994; Joubert et al., 1997) have tried to conceptualise the decision between the two methods following an exclusion principle of certain criteria. Since this can either lead to an oversimplification of the choice of the method or to a too complex decision structure following the exclusion principle, we want to emphasise only two important strands of argumentation here. If the time horizon to conduct the analysis is restricted and the number of values that would need to be converted into monetary terms is considerable, then CBA shows not to be the optimal solution since it can not fulfil the analytic requirements thoroughly while equally follow tight time schedules. Another such strong argument for one of the methods can be given in terms of objectives: if the outcome 
is not relevant in terms of bringing about the most consensual solution for all, but rather just a strong argument in terms of monetary values for or against a certain project, then clearly CBA is the method that is more desirable here. Apart from these two cases, we find it difficult to suggest a certain framework along which the decision for one of the methods can be made. The starting point of a project is usually more complex and difficult and a weighing of all the arguments mentioned in this paper needs to be done by the analyst to make use of the method most suitable for the respective case.

\section{Conclusions}

In the present paper, the main aim was to look at the decision support instruments of CBA and MCA in their ability to bring transparency, equity and efficiency in decisions taken for protective measures against natural hazards. As was shown this application area is equally addressed by civic, geoscientific, legal or meteorological as well as environmental, economic, ecological and social interest groups. CBA and MCA proved to be tools that can bring together this multidisciplinary field of research down to a decision basis for the actual instalment of protection measures against natural hazards. The discussion of the two methods underlined that they depart from similar ideas but still deviate from one another in terms of their operationalisation. The implementation guidelines demonstrated how the diverging characteristics between the methods can be used for different preconditions for the assessment of alternative projects within natural hazard management.

The presented work remains theoretical. Numerous applications in natural hazards have been frequently carried out, nonetheless there remains potential for the consideration of economic aspects. The aim of this paper was to give a conceptual overview and discussion of the two methods from an economic viewpoint since they are becoming of more and more interest to the natural hazard science community.

In conclusion, both, CBA and MCA, rooted in socioeconomic research, have shown to provide an innovative platform beyond their discipline for trans- as well as multidisciplinary research such as natural hazard management is.

Acknowledgement. This paper originated as part of two socioeconomic projects at alpS - Centre for Natural Hazard Management (Innsbruck, Austria) in cooperation with the Institute of Public Finance, University of Innsbruck (Austria). Financial support by the Hypo Tirol Bank and ILF is gratefully acknowledged. We would like to thank two anonymous referees for their helpful comments and reviews of an earlier version of this paper.

Edited by: T. Glade

Reviewed by: two referees

\section{References}

Ammann, W.: Integrales Risikomanagement - der gemeinsame Weg in die Zukunft, Bündnerwald, 5, 14-17, 2001.

Belton, V. and Stewart, T. J.: Multiple Criteria Decision Analysis: An Integrated Approach, Kluwer Academic Publishers, 2002.

Belton, V. and Vickers, S.: Use of simple Multi-Attribute Value Function incorporating visual interactive sensitivity analysis for Multiple Criteria Decision Making, in: Readings in Multiple Criteria Decision Aid, edited by: Bana e Costa, C. A., Berlin, Springer, 320-334, 1990.

Boardman, A. E., Greenberg, D. H., Vining, A. R., and Weimer, D. L.: Cost-Benefit Analysis - Concepts and Practice, Prentice Hall, New Jersey, 2001.

Bosch, H. and Kahn, M.: Approaches and Methods to Prioritization of Adaption Activities, LEG Regional Workshop, Samoa, 2003.

Brouwer, R. and Van Ek, R.: Integrated ecological, economic and social impact assessment of alternative flood control policies in the Netherlands, Ecological Economics, 50, 1-21, 2004.

Brown, K., Adger, W.N., Tompkins, E., Bacon, P., Shim, D. and Young, K.: Trade-off analysis for marine protected area management. Ecological Economics, 37, 417-434, 2001.

Bründl, M., Mc Alpin, M. C., Gruber, U., and Fuchs, S.: CostBenefit Analysis of Measures for Avalanche Risk Reduction - a Case Study from Davos, Switzerland, forthcoming in: Risk 21 - Coping with risks due to natural hazards in the 21 Century, Conference Proceedings, Davos, 2005.

Cavallaro, F. and Ciraolo, L.: A Multicriteria Approach to evaluate Wind Energy Pants on an Italian Island, Energy Policy, 33, 235244, 2005.

Connolly, S. and Munro, A.: Economics of The Public Sector, Prentice Hall, 1999.

De Marchi, B., Funtowicz, S. O., Lo Casciao, S., and Munda, G.: Combining participative and institutional approaches with multicriteria evaluation, An empirical study for water issues in Troina, Sicily, Ecological Economics, 34, 267-282, 2000.

Degenhardt, S., Hampicke, U., Holm-Müller, K., Jaedicke, W., and Pfeiffer, C.: Zahlungsbereitschaft für Naturschutzprogramme, Angewandte Landschaftsökologie, 25, Bonn-Bad Godesberg, 1998.

Dogson, J., Spackmann, M., Pearman, A., and Philips, L.: MultiCriteria Analysis: A Manual, Office of the Deputy Prime Minister, Creating sustainable communities, 2001.

Edwards-Jones, G., Davies, B., and Hussain, S.: Ecological Economics, An Introduction, Blackwell Science, London, 2000.

Elsasser, P.: Der Erholungswert des Waldes, Monetäre Bewertung der Erholungsleistung ausgewählter Wälder in Deutschland, Schriften zur Forstökonomie, 11, 218-225, 1996.

Fandel, G. and Spronk, J.: Multiple Criteria-Decision Methods and Applications, Springer, Berlin, 1983.

Fuchs, S. and McAlpin, M. C.: The Net Benefit of Public Expenditures on Avalanche Defence Structures in the Municipality of Davos, Switzerland, Nat. Hazards Earth Syst. Sci., 5, 319-330, 2005.

Gamper, C. D.: Building Energy Scenarios for Eastern Styria (Austria) using Multi Criteria Mapping with the Inclusion of Participatory Methods, Master of Science Thesis, University of Edinburgh, 2004. 
Garrod, G. and Kenneth, G. W.: Economic Valuation of the Environment: Methods and Case Studies, Edward Elgar, Cheltenham, 1999.

Graham, J. E. and Hall, W. W.: Hurricanes, Housing Market Activity, and Coastal Real Estate Values, The Appraisal Journal, 379-387, October 2001.

Hackl, F. and Pruckner, G. J.: Die Kosten/Nutzen Analyse als Bewertungsinstrument der Umweltpolitik, in: Einführung in die Umweltpolitik, edited by: Bartel, R., Hackl, F., Vahlen, München, 83-100, 1994.

Hanley, N. and Spash, C. J.: Cost-Benefit Analysis and the Environment, Edward Elgar, Cheltenham, 1993.

International Society on MCDM.: International Society on MultiCriteria Decision Making, http://www.terry.uga.edu/mcdm/ (last access 17.6.2004), 2004.

Joubert, A. R., Leiman, A., Klerk, H. M., Katua, S., and Aggenbach, J. C.: Fynbos (fine bush) vegetation and the supply of water: a comparison of multi-criteria decision analysis and costbenefit analysis, Ecological Economics, 22, 123-140, 1997.

Kämmerer, S., Schmitz, P. M., and Wiegand, S.: Monetäre Bewertung der Kulturlandschaft in Baden-Württemberg, in: Nachhaltige Land- und Forstwirtschaft. Expertisen., edited by: Linckh, G., Sprich, H., Flaig, H., and Mohr, H., Springer, Berlin, 77-97, 1996.

Kienholz, H., Krummenacher, B., Kipfer, A., and Perret, S.: Aspects of integral risk management in practice - considerations with respect to mountain hazards in Switzerland, Österreichische Wasser- und Abfallwirtschaft, 56, 43-50, 2004.

Löwenstein, W.: Reisekostenmethode und bedingte Bewertungsmethode, Schriften zur Forstökonomie, Band 6, 206pp., 1994.

Mueller, D.: Public Choice III, Cambridge University Press, 2003.

Munda, G.: Multicriteria Evaluation in a Fuzzy Environment, Theory and Applications in Ecological Economics, Physica, Heidelberg, 1995.

Navrud, S. and Pruckner, G. J.: Environmental Valuation - To use or not to use? A comparative study of the USA and Europe, Environmental and Resource Economics, 10, 1-25, 1997.

Omann, I.: Multi-Criteria Decision Aid as an Approach for Sustainable Development Analysis and Implementation, $\mathrm{PhD}$ Thesis, Karl-Franzens University, Graz, 2004.
Pruckner, G.J.: Die ökonomische Quantifizierung natürlicher Ressourcen. Eine Bewertung überbetrieblicher Leistungen der österreichischen Land- und Forstwirtschaft, PhD Thesis Johannes-Keppler University, Linz, 1993.

Pruckner, G. J.: Contingent Valuation - The public debate and environmental applications, Zeitschrift für Umweltpolitik und Umweltrecht, 4, 1995.

Römer, A. U.: Der kontingente Bewertungsansatz. Eine geeignete Methode zur Bewertung umweltverbessernder Maßnahmen?, Zeitschrift für Umweltpolitik und Umweltrecht, 14, 411-456, 1991.

Rosen, S.: Hedonic Prices and Implicit Markets: Product Differentiation in Pure Competition, The Journal of Political Economy, 82, 1, 34-55, 1974.

Steininger, K. W. and Weck-Hannemann, H.: Global Environmental Change in Alpine Regions: Recognition, Impact, Adaptation and Mitigation, New Horizons in Environmental Economics, Edward Elgar, Cheltenham, 2002.

Stirling, A. and Mayer, S.: A Precautionary Approach to Technology Appraisal? - A multi-criteria mapping of genetic modification in UK agriculture, TA-Datenbank-Nachrichten, 3/9, 39-51, 2000.

Thöni, M.: Was sind Schutzmaßnahmen wert?, Journal of Torrent, Avalanches, Landslide and Rock Fall Engineering, 153, 67-75, 2005.

Van Pelt, M. J. F.: Environment and project appraisal: lessons from two cases, The Annals of Regional Science, 28, 55-76, 1994.

Vincke, P., Gassner, M., and Roy, B.: Multicriteria Decision-Aid, Wiley \& Sons, West Sussex, 1989.

WCED, World Commission on Environment and Development.: Our Common Future, Oxford University Press, Oxford, 1983.

Weck-Hannemann, H.: Was ist der Wald uns wert? Eine Einschätzung aus ökonomischer Sicht, Schweizerische Zeitschrift für Forstwesen, 2, 95-110, 1994.

Wilhelm, C.: Wirtschaftlichkeit im Lawinenschutz, Swiss Federal Institute of Snow and Avalanche Research, Davos, 1997.

Wilhelm, C.: Risikoanalyse bei gravitativen Naturgefahren. Fallbeispiele und Daten, Bundesamt für Umwelt, Wald und Landschaft, BUWAL, 107/II, Bern, 1999. 